\title{
La geografia a la Universitat Autònoma de Barcelona: un projecte d'Enric Lluch (II)*
}

\author{
Antoni F. Tulla Pujol \\ Maria Dolors Garcia Ramon \\ Helena Estalella Boadella \\ Universitat Autònoma de Barcelona. Departament de Geografia \\ antoni.tulla@uab.cat \\ mariadolors.garcia.ramon@uab.cat \\ helena.estalella@uab.cat
}

\section{Resum}

S'ha complert mig segle d'ensenyament de la geografia a la UAB (de 1969 a 2019). Al present article se n'hi expliquen els primers vint anys, fins a completar el desenvolupament de la Llei de reforma universitària (LRU) a la nostra universitat, i s'hi dona a conèixer quin era l'equip acadèmic que va acompanyar Enric Lluch (1928-2012) en aquesta experiència. També s'hi introdueix la geografia que recollia els enfocaments innovadors que arribaven principalment de França, dels països anglosaxons i d'Itàlia, i s'hi mostra la formació docent i investigadora del professorat, a més del desenvolupament de les eines científiques que han fet possible l'assentament de la geografia a la UAB. Bàsicament, es tracta d'explicar-hi la recerca, els contactes internacionals, els laboratoris i la revista Documents d'Anàlisi Geogràfica, entre d'altres qüestions. A les conclusions s'hi valora l'esforç col-lectiu que ha fet possible que aquest procés hagi continuat amb èxit, tant a Bellaterra com a Girona.

Paraules clau: Documents d'Anàlisi Geogràfica; Enric Lluch; geografia a la Universitat Autònoma de Barcelona; innovació docent; recerca científica

* Aquesta és la segona part de l'article mitjançant el qual volem retre homenatge al professor Enric Lluch i Martín (1928-2012), introductor de la geografia a la UAB. La primera part la trobareu a Documents d'Anàlisi Geogràfica, núm. 2019, vol. 65 (2), p. 207-242. 
Resumen. La geografia en la Universitat Autònoma de Barcelona: un proyecto de Enric Lluch (II)

Se ha cumplido medio siglo de enseñanza de la geografía en la UAB (de 1969 a 2019). En el presente artículo se explican sus primeros veinte años hasta completar el desarrollo de la Ley de reforma universitaria (LRU) en nuestra universidad y se da a conocer cuál era el equipo académico que acompañó a Enric Lluch (1928-2012) en esta experiencia. Se introduce la geografía que recogía los enfoques innovadores que llegaban principalmente de Francia, de los países anglosajones y de Italia, y se muestra la formación docente e investigadora del profesorado, así como el desarrollo de las herramientas científicas que han hecho posible el asentamiento de la geografía en la UAB. Básicamente, se trata de contar la investigación, los contactos internacionales, los laboratorios y la revista Documents d'Anàlisi Geogràfica, entre otros aspectos. En las conclusiones se valora el esfuerzo colectivo que ha hecho posible que este proceso haya continuado con éxito, tanto en Bellaterra como en Girona.

Palabras clave: Documents d'Anàlisi Geogràfica; Enric Lluch; geografía en la Universitat Autònoma de Barcelona; innovación docente; investigación científica

Résumé. La géographie à l'Universitat Autònoma de Barcelona : un projet d'Enric Lluch (II)

Cinquante ans d'enseignement de la Géographie à l'UAB (1969 à 2019) viennent d'être célébrés. Les 20 premières années sont présentées, jusqu'à l'achèvement du développement de la loi sur la réforme de l'université (LRU) à l'UAB, ainsi que l'équipe académique qui a accompagné Enric Lluch (1928-2012) dans cette expérience. On a introduit la géographie qui a rassemblé les approches novatrices venues principalement de la France, des pays anglo-saxons et de l'Italie. Dans cette deuxième partie, nous expliquons la formation des enseignants en matière d'enseignement et de recherche, ainsi que le développement des outils scientifiques qui ont permis l'établissement de la géographie à l'UAB. Il s'agit essentiellement de recherche, de contacts internationaux, de laboratoires et du journal Documents d'Anàlisi Geogràfica, entre autres. Dans les conclusions, l'effort collectif qui a permis à ce processus de se poursuivre avec succès, à Bellaterra comme à Girona, est valorisé.

Mots-clés: Documents d'Anàlisi Geogràfica; Enric Lluch; géographie à l'Universitat Autònoma de Barcelona; innovation de l'enseignement; recherche scientifique

Abstract. Geography at the Universitat Autònoma de Barcelona: A project of Enric Lluch (II)

Geography has been taught at the Autonomous University of Barcelona (UAB) for 50 years (1969-2019). This paper explores the first 20 years of geography until the entry into force of the University Reform Law (LRU) at the UAB and the academic team that accompanied Enric Lluch (1928-2012) in this experience. The introduction of geography based on innovative approaches coming mainly from France, English-speaking countries and Italy is discussed. In this second part we also describe the teaching and research training of teachers, and the development of scientific tools that have made the establishment of geography in the UAB possible: basically, research, international contacts, laboratories and the Documents d'Anàlisi Geogràfica journal, among others. To conclude, the collective effort that has contributed to the success of this process both in Bellaterra and in Girona is examined.

Keywords: Documents d'Anàlisi Geogràfica; Enric Lluch; geography at the Universitat Autònoma de Barcelona; teaching innovation; scientific research 


\section{Sumari}

1. Introducció: Estructura de l'article

2. Jornades de Formació i de Docència: El professorat visitant

3. Documents d'Anàlisi Geogràfica: Origen i desenvolupament
4. Les eines científiques per al desenvolupament de la geografia a la UAB 5. La promoció de la recerca en geografia: Projecció cívica i cultural

6. Reflexions finals

Referències bibliogràfiques

\section{Introducció: Estructura de l'article}

Ara fa cinquanta anys que s'imparteixen classes de geografia a la Universitat Autònoma de Barcelona (UAB) i ens ha semblat oportú poder explicar amb un cert detall quin tipus de disciplina s'hi ensenyava $\mathrm{i}$ qui en va ser docent a l'inici. El període que tractarem serà el comprès entre els cursos 1969-1970 i 1989-1990, des del primer professor d'aquesta disciplina, Enric Lluch i Martín (1928-2012), fins que es va completar el desplegament de la Llei de reforma universitària $(L R U)^{1}$ a la UAB, amb el Decret de departaments de la LRU (12 de desembre de 1984). La UAB, creada l'any 1968 (Riquer i Molinero, 2018), va representar un nou enfocament acadèmic de la docència i la recerca universitàries, basades en les noves tendències científiques a Europa i a l'Amèrica del Nord.

Ens ha semblat important poder deixar constància dels grans trets del projecte de la nova geografia a la UAB que va endegar Enric Lluch el 1969. Tanmateix, podem trobar un recull sistemàtic de la seva obra relacionada amb la geografia i el territori en el treball elaborat per Abel Albet (2007). Aquí pretenem recordar bàsicament les aportacions que va realitzar en el desenvolupament de l'ensenyament i la recerca, així com en la formació que rebia el professorat per fer-ho possible. L'estructura d'aquest article comença amb la formació docent i investigadora, i a continuació s'hi expliquen la creació i el desenvolupament del $\mathrm{DAG}^{2}$ i dels principals projectes de recerca que va promoure l'Enric, primer, i el professorat que l'acompanyava, després. La creació dels laboratoris i els contactes internacionals varen ajudar a consolidar el projecte iniciat l'any 1969. Actualment, el record acadèmic d'aquests primers anys del Departament el podem palpar quotidianament amb l'Aula 402 (B9/0016), dedicada a Pau Vila i Dinarès, doctor honoris causa per la UAB el 1979, un dels mestres d'Enric Lluch i Martín, a qui s'ha dedicat el Seminari de Postgrau de Geografia (B9/1058).

La metodologia emprada s'ha fonamentat en el material de les persones autores aportat i discutit en grup, juntament amb un treball de recerca sobre

1. Ley Orgánica 11/1983, de 25 de agosto, de Reforma Universitaria.

2. Documents d'Anàlisi Geogràfica, revista del Departament de Geografia de la UAB, i també de la UdG des de l'any 1994. 
els arxius del Departament, i en una part de la documentació lliurada per Montserrat Galera ${ }^{3}$ del material administratiu i didàctic d'Enric Lluch. S'ha completat amb el material bibliogràfic i de recerca disponible ${ }^{4}$.

\section{Jornades de Formació i de Docència: El professorat visitant}

Des del principi, alguns divendres es dedicaven a desenvolupar un seminari formatiu. Els escrits corresponents podien ser publicats en els documents de treball del Departament de manera global o parcial. N'hi havia de diversos tipus. Per exemple, el curs 1970-1971 en Jordi Borja va fer deu sessions de dues hores sobre l'anàlisi sociogeogràfica de Barcelona des del Pla Cerdà fins al 1970, activitat que corresponia a una temàtica conceptual. De forma complementària, Laura Zumin va impartir un curset de geografia urbana, amb assistència del professorat i l'alumnat de segon i tercer curs, que tractava sobre autors francesos i italians. En canvi, Enric Lluch va realitzar una anàlisi de la procedència territorial i social dels estudiants de la Facultat de Lletres, introduint un debat sobre les àrees d'influència de la UAB i els motius d'aquesta mobilitat.

Més endavant, durant els mesos de juny, juliol o setembre, es varen organitzar cursos per al professorat que tractaven sobre formació i debat entorn de temes considerats bàsics o innovadors. El 1972 va haver-hi un curset d'anàlisi de fotointerpretació a la Facultat de Geologia de la UB impartit per J.M. Obiols. El 1973 es va impartir un curs d'informàtica bàsica a la Facultat de Ciències Econòmiques de la UAB (Escola Oficial d'Idiomes de la UB a Barcelona) i també un d'introducció a les matemàtiques per a un grup reduït de docents que va ser impartit per Robert Estalella. El 1973 es va fer un curs d'iniciació al llenguatge Basic per part de Diana Garrigosa a la Facultat de Ciències Econòmiques de Bellaterra, amb assistència del professorat del Departament. En aquells anys, el Centre de Càlcul de la UAB oferia cursos de programació en llenguatge Fortran, necessari per manejar les grans computadores VAX, utilitzades en les primeres tesis doctorals i que encara anaven amb targetes perforades. Tanmateix, alguns membres del Departament empràvem la Compucord, un ordinador personal que funcionava amb targetes magnètiques $\mathrm{i}$ llenguatge Basic.

Enric Lluch va ser promotor de molts cursos impartits per especialistes d'altres països. En aquest sentit, el mes de juny de 1971, el professor Yves Lacoste va fer un curset de la nova geografia integrada que va ser organitzat conjuntament amb el Departament de Geografia de la UB, el Col.legi d'Ar-

3. Cessió del material didàctic, de recerca i d'ús administratiu d'Enric Lluch i Martín a la Biblioteca d'Humanitats l'any 2014. L'està ordenant i classificant la professora Pilar Riera.

4. Volíem agrair a Montserrat Izquierdo i a Joan Pie, de la secretaria, que hagin buscat alguns documents en els arxius del Departament, a les companyes Montserrat Terradas i Isabel Salamaña, de Girona, i Rosa Ascon i Pilar Riera, de Bellaterra, així com a Pau Alegre, que ens hagin facilitat documentació i aclariments. També volem mostrar la nostra gratitud a Joan Manuel Soriano per haver fet la correcció lingüística de l'article. 
quitectes, l'Escola d'Arquitectura, el Col-legi d'Aparelladors i ESADE. L'estiu de 1972 es va realitzar a Sant Cugat un seminari de presentació i debat de noves tendències en la geografia urbana, amb assistència de tot el professorat i la participació com a ponents de Bartomeu Barceló (Ciutat de Mallorca), Robert Ferras (Montpeller) i Jordi Borja. En el mateix sentit, el mes de setembre de 1973 es va organitzar un curs sobre la nova geografia teorètica impartit per Tarik Okyay (Okyay, Yazar y Altaban, 1975), professor de la Facultat d'Arquitectura de la Middle East Technical University (METU, Ankara), que estava realitzant el seu doctorat al Departament de Geografia de la Universitat de Bristol, on s'havien conegut amb Antoni Tulla. Hi varen assistir arquitectes, geògrafs i altres especialistes en temes territorials, a més del professorat del Departament. Durant la introducció va fer una crítica de l'enfocament neoclàssic de la teoria de localització basant-se en els treballs recents de David Harvey (1973) i Manuel Castells (1972), però després va explicar amb detall aquests models de localització i uns altres de l'àmbit quantitatiu, com ara les cadenes de Markov, en nou sessions (del 18 al 20 de setembre de 1973). Prèviament es va organitzar un curset propedèutic d'economia i d'estadística impartit per Antoni Tulla, de sis sessions (del 15 al 17 de setembre de 1973), per al professorat de la divisió i per a qui ho demanés dels inscrits al curs de Tarik Okyay. Aquestes són activitats que es varen anar repetint durant molts anys, que sempre s'organitzaven en complicitat amb altres institucions i en les quals s'oferien temes innovadors i poc coneguts llavors en el nostre país.

Un altre espai formatiu i de debat varen ser les escoles d'estiu de Rosa Sensat per a mestres i llicenciats, on Enric Lluch i Pilar Benejam havien col.laborat des de feia molts anys. A part d'impartir cursos a l'Escola d'Estiu, també es va assistir a activitats formatives sobre temes innovadors, de contingut $\mathrm{i}$ de didàctica per millorar las aptituds pedagògiques del professorat. En una vessant més investigadora i de compromís social, cal esmentar la participació d'una part del professorat en l'àmbit viII («Ordenació del territori»), on es varen discutir temes diversos, des de la divisió territorial de Catalunya (La Seu d'Urgell, 14 de novembre de 1976) fins a l'Eix Transversal de Catalunya (Vic, 1976). Aquest àmbit va ser l'origen de la Societat Catalana d'Ordenació del Territori (SCOT), amb una composició de diverses professions que tenien en comú l'interès per la problemàtica territorial, un dels objectius de la geografia que Enric Lluch va iniciar a la UAB. Un altre àmbit, el de l'agricultura, també va tenir interès per a una part del professorat, la qual cosa queda demostrada perquè aquesta temàtica es pot trobar en moltes investigacions i tesis doctorals del Departament, que ha estat lligat a una altra societat filial de l'IEC, l'Institut Català d'Estudis Agraris —inicialment ubicat a l'Escola Industrial i amb la majoria de membres enginyers agrònoms-, que es va anar obrint als economistes, als geògrafs i als sociòlegs, a part de la pagesia més interessada en els nous coneixements i el debat.

Durant la dècada de 1980 els llicenciats varen iniciar l'obtenció de beques predoctorals (Fulbright Caixa, MEC, universitats de destí, etc.) i això va permetre que estudiessin en universitats americanes com ara Arizona, Boston, 
Clark, Los Angeles i Wisconsin-Madison, o també d'Anglaterra i França. Al mateix temps, les beques de FPI del MEC també finançaven estades de tres mesos en universitats estrangeres.

Finalment, cal esmentar les estades de professorat visitant arran de contactes establerts principalment amb M. Dolors Garcia Ramon, com ara Anne Buttimer (maig de 1976) o David Harvey (maig de 1977), que van fer les seves primeres visites a l'Estat espanyol. Així mateix, l'organització del seminari Gènere i Món Rural l'any 1987 (Garcia Ramon, 1989), en què varen participar Janice Monk, Janet Momsen i Martine Berlan, entre d'altres, va facilitar la consolidació de l'enfocament de gènere en la geografia. Un visitant també molt especial va ser David W. Rhind $(1980,1991)$, que va introduir els SIG a Europa durant la dècada de 1960. Graduat a la Universitat de Bristol, conferenciant i lector a la Universitat de Durham (1973-1981), professor de Geografia al Birkbeck College de la Universitat de Londres (1982-1992) i director general de l'Ordinance Survey del Regne Unit (1992-1998), va fer algunes conferències al nostre departament (1988 i 1990) i va acollir joves professors, com ara Joan Nunes. Aquestes relacions internacionals i d'altres varen encetar moltes oportunitats de colllaboració per conèixer noves orientacions de la geografia i facilitar que el professorat jove i els becaris poguessin fer estades en altres universitats del món.

Per completar aquesta visió caldria esmentar que el mes de setembre de 1982 M. Dolors Garcia Ramon i Antoni F. Tulla varen ser convidats a la Jornada sobre Desenvolupament Nacional i Regional a la Mediterrània (Departament de Geografia de la Universitat de Durham), on varen conèixer especialistes de diversos països (Ray Hudson, Jim Lewis, Joao Ferrao, Dina Vaiou, Costis Hadjimichalis, etc.) que després establirien relacions acadèmiques amb el Departament. Tanmateix, el més important és destacar que aquests contactes ens van permetre participar en una xarxa Erasmus encapçalada per Durham, en el programa pilot de 1985 i des de 1986 fins a 1995, tal com explica Costis Hadjimichalis (2017) en un homenatge a Ray Hudson.

\section{Documents d'Anàlisi Geogràfica: Origen i desenvolupament}

Una de les primeres contribucions importants del Departament de Geografia de la UAB a la geografia catalana i espanyola va ser la publicació de la revista Documents d'Anàlisi Geogràfica, impulsada per Enric Lluch des de l'any 1974, quan s'havia creat "per decret de Madrid» la llicenciatura de Geografia als departaments on ja hi havia ensenyaments d'aquesta disciplina (Garcia Ramon, 2013). L'Enric creia fermament que la publicació serviria per projectar a Catalunya, a Espanya i a la resta del món la manera d'entendre la geografia a la $\mathrm{UAB}$, és a dir, entesa com a ciència social i des d'una perspectiva crítica.

Obtenir finançament no era cosa facil en aquells moments, però gràcies a la tossuderia de l'Enric se'n va aconseguir, i els esforços fets al llarg de 1973 van culminar en la publicació del primer número al mes de gener de 1974. Cal dir que en aquell moment no es tractava d'una revista regular i periòdica, sinó 
que més aviat hi havia la idea de produir uns working papers. Efectivament, des de l'any 1974 fins al 1981 es van anar publicant tres sèries del que hem anomenat "pre-DAG", els Documents d'Anàlisi Urbana, dels quals se'n van editar tres números (el gener de 1974, el desembre de 1974 i el desembre de 1975), els Documents d'Anàlisi Metodològica en Geografia, dels quals se'n van editar dos números (el desembre de 1977 i el febrer de 1981) i els Documents d'Anàlisi Territorial, dels quals se'n van editar dos números (el juliol de $1975 \mathrm{i}$ el juliol de 1976). Encara que Enric Lluch estava al darrere de totes les publicacions de la sèrie d'urbana, també hi van desenvolupar un paper significatiu Laura Zumin i sobretot Jordi Borja, que acabava de tornar de Xile i tenia molts contactes amb els estudiosos de l'Amèrica Llatina. En la sèrie metodològica $\mathrm{i}$ territorial van estar molt actius M. Dolors Garcia i Antoni F. Tulla. Les sèries d'urbana i metodològica tenien un enfocament molt crític (estàvem en plena transició política), però la sèrie territorial mostrava, en canvi, unes connotacions molt més tècniques, fruit dels contactes amb la geografia teoreticoquantitativa que en aquells moments havia establert la geografia de la UAB.

A principis de la dècada de 1980 el Departament de Geografia també va promocionar la publicació de dos documents específics que van ser importants: Una aplicació del Programa M.A.P a Catalunya (1982), editat per Pau Alegre, i La nova divisió territorial de Catalunya, editat per Pilar Riera (1983). L'un era una col-laboració metodològica amb l'Administració catalana i l'altre recollia el debat sobre com havia de ser la divisió territorial a Catalunya.

Però a partir de 1982, encoratjats per Enric Lluch des del Departament i animats per José Manuel Blecua Perdices, en aquell moment director del Servei de Publicacions de la UAB, es va començar una nova etapa de les publicacions geogràfiques, en què la revista Documents d'Anàlisi Geogràfica (DAG) va encetar una periodicitat bianual. A diferència de les sèries anteriors, els números no eren habitualment de caràcter monogràfic i llur contingut es presentava en una secció d'articles de fons i una altra de notes i documentació. Com que l'Enric no volia (o no li agradava) ser el protagonista de gaires iniciatives, va proposar la M. Dolors Garcia de directora i cap de redacció, que va acceptar l'oferiment perquè sabia que l'Enric estava al darrere del projecte. Al Consell de Redacció hi havia el mateix Enric Lluch, a més de Jordi Borja, Joan Sabí, Antoni F. Tulla i Maria Dolors Garcia Ramon . Poc després s'hi van incorporar Joan Nogué i Maria Villanueva.

Fins l'any 1989 se'n van publicar quinze números, amb dos monogràfics amb una aportació econòmica, l'un tractava sobre l'Àrea Metropolitana de Barcelona i l'altre sobre el Programa MAB-6 (Urgellet-Baridà). Seguint l'esperit del que sempre ens deia l'Enric, el contingut era molt obert, tant des de la perspectiva interdisciplinària (història, arquitectura, etc.) com de l'origen de l'autoria. Així, es va intentar que la revista no fos només el mirall del que feiem al Departament, com era el costum en molts d'aquest tipus de publicacions espanyoles, sinó que també hi havia articles de gent de Girona, Barcelona, Mallorca, Saragossa, Canàries, Madrid i els EUA. També cal dir que a la secció «Notes i documentació» s'hi van editar ressenyes de congressos celebrats a 
Anglaterra i França, ja que volíem que la revista fos en la geografia catalana i espanyola com una finestra cap a la resta del món.

La temàtica d'aquests números és sobretot de geografia humana i hi havia articles molt innovadors per la seva època, com ara, per exemple, els que tractaven el model de Hägerstrand, la geografia humanista o la geografia del gènere.

\section{Les eines científiques per al desenvolupament de la geografia a la UAB}

Al principi, el material didàctic, alguns llibres i revistes i els mapes van ser fonamentals i es guardaven en el despatx seminari que tenia el Departament de Ciències Socials a la Casa de Cultura de l'Ajuntament de Sant Cugat del Vallès (1969-1973). Més endavant, des del mes d'octubre de 1973, al campus de Bellaterra s'hi varen anar creant espais específics per a cadascun d'aquests serveis. Sense voluntat de ser exhaustius en citarem els elements més significatius.

\subsection{Les pràctiques, el material didàctic $i$ les innovacions pedagògiques}

A partir del curs 1969-1970 es van realitzar a Sant Cugat les pràctiques següents: excursions al Montseny, al Baix Llobregat i a l'Alt Llobregat; la conferència de Manuel Ribes Piera sobre urbanística i planejament regional, i el curset de M. Dolors Garcia Ramon sobre geografia cultural (la pesca a Cuba). Al CUG es varen organitzar les excursions a Olot i a la Costa Brava, i Montserrat Moli hi va impartir un curset sobre l'àrea suburbana de Girona. Aquest va ser el model habitual.

La innovació didàctica ha estat cabdal en el desplegament de la geografia a la UAB. Per aquest motiu, ben aviat Enric Lluch va incorporar Pilar Benejam en el projecte (Benejam, 2014). Primerament, en l'enfocament pedagògic en la docència de cada assignatura $\mathrm{i}$, després, en l'elaboració de la didàctica de la geografia o de les ciències socials. Des que es va instaurar la titulació de Geografia - l'any acadèmic 1977-1978 - durant el quart curs els estudiants varen aprendre a ensenyar davant de l'alumnat de secundària. Aquest ha estat un element característic, tant del professorat com de l'alumnat de Geografia, tal com expliquen Pau Alegre et al. (1983).

La preparació de les assignatures sempre es feia en equip. Tant si l'assignatura es dividia entre el professorat com si n'hi havia diversos grups d'una mateixa àrea. S'organitzaven reunions entre juny i juliol per buscar bibliografia i exemples que es presentaven i es discutien col-lectivament. L'estada de diversos membres del professorat a l'estranger va afavorir que es poguessin emprar exemples a través de la bibliografia o de l'intercanvi d'opinions amb col-legues d'altres departaments, la qual cosa va ajudar a innovar tant des del punt de vista conceptual com de l'enfocament. També hi ajudaven les sessions formatives, que sovint s'orientaven cap a les noves assignatures. Aquesta preparació en grup feia més facil l'avaluació col-lectiva. 


\subsection{L'avaluació}

El seguiment dels resultats de l'alumnat era present en la docència de la Geografia (UAB). En elaborar els programes i els continguts, es tenia en compte quines eren les pràctiques que calia fer i quins resultats s'esperava obtenir dels estudiants. El professorat de cada assignatura feia un seguiment col-lectiu de l'alumnat, i quan va haver-hi la llicenciatura de Geografia s'avaluava cada estudiant pel conjunt de les matèries que cursava.

A fi de millorar l'aprenentatge dels universitaris, es realitzaven pocs exàmens i molts treballs i pràctiques. De fet, era una avaluació continuada trimestralment. Es va procurar distribuir aquestes activitats al llarg del curs, a fi que es concentressin al mes de maig. En aquest sentit, s'acordava un calendari de lliurament de treballs en les reunions de docència.

\subsection{La biblioteca i l'hemeroteca}

Durant els primers anys alguns llibres i manuals es trobaven al Seminari de Geografia del Departament de Ciències Socials, a la Casa de Cultura de Sant Cugat. El curs 1971-1972 es va crear una biblioteca per a tota la Facultat de Lletres a la planta baixa de la Casa de Cultura, en poder disposar de més aulari en el claustre del monestir. En traslladar-se la Facultat al campus de Bellaterra, el curs 1973-1974 es va habilitar l'espiga B7 senar planta baixa per situar-hi la biblioteca. El curs 1978-1979 s'habilità part de la planta primera de l'esmentada espiga com a sala de revistes. El curs 1986-1987 es va construir un nou edifici (B9 senar), que, a més de tenir 38 despatxos i la sala d'actes, es destinà a biblioteca i a sala de revistes. En el curs 1997-1998 va entrar en funcionament la Biblioteca d'Humanitats (edifici L), que donaria servei a les facultats de Ciències de l'Educació; de Filosofia i Lletres; de Psicologia, i de Traducció i Interpretació. La cartoteca va ser instal.lada a la segona planta, orientació sud. L'hemeroteca (edifici B9 senar) va ocupar la vella biblioteca. El fons promogut per Geografia va orientar-se bàsicament a disposar de manuals i bibliografia docent per a la llicenciatura, però també per donar suport a les línies principals de recerca aprofitant les convocatòries del MEC i la UAB per adquirir llibres. També es van utilitzar recursos dels projectes de recerca.

De bon començament l'Enric va voler tenir una hemeroteca de geografia molt completa a la UAB, amb l'objectiu de disposar d'una revista de cada país europeu i americà, a més de les més significatives en cada especialitat. La revista crítica Hérodote, iniciada el 1976 per Yves Lacoste, pot ser una imatge del que es pretenia aconseguir, a més de les publicacions més habituals. Hi va haver convocatòries públiques per completar anys anteriors de les que ja existien catalogades i l'Enric sempre estava a l'aguait, actitud que es va transmetre a la resta de col-legues. Un fet remarcable fou haver aconseguit uns 150 intercanvis de la revista DAG amb publicacions de reconegut renom, la qual cosa va posar en valor la nostra revista. Al segle Xxi s'ha canviat el model, atès que s'han imposat les publicacions electròniques que substitueixen moltes de les editades 
en paper. També es va promoure l'intercanvi entre biblioteques tendint a una única subscripció per universitat. En qualsevol cas, de forma electrònica o en paper, l'hemeroteca és un dels grans actius de la geografia a la UAB.

\subsection{La cartoteca}

Els mapes es guardaven al Seminari de Geografia (Departament de Ciències Socials) de la Casa de Cultura de Sant Cugat del Vallès (1969-1973). Des de 1973 fins a 1976 es va posar el material cartogràfic al despatx 6 de Geografia (espiga B9 parell, primera planta). El curs 1976-1977 Pau Alegre, professor de cartografia, va poder habilitar l'aula $36 \mathrm{com}$ a cartoteca, encara que era compartida amb les classes de segon cicle de l'especialitat. El curs 1981-1982 es va convertir l'aula 38 exclusivament en cartoteca. El nombre de col-leccions de mapes, fotografies aèries i atles augmentava constantment $\mathrm{i}$ es necessitava més espai per ordenar i classificar el material, però també per consultar-lo. El curs 1983-1984 es va remodelar tota l'espiga B9 parell, planta baixa, mantenint-hi 7 aules, creant-hi 13 despatxos per al professorat de geografia, el laboratori de geografia física i una gran cartoteca en l'espai dedicat a Pau Vila. En construirse la Biblioteca d'Humanitats, la cartoteca s'hi va traslladar el 1997.

El servei de cartoteca ha tingut cura de l'inventari i l'arxiu dels documents gràfics en dues dimensions (mapes, plànols i fotografia aèria vertical). Ateses les característiques especials de format i d'ús que presenten, s'ha cregut convenient de situar-los en una sala especial per facilitar-ne l'accés, l'arxiu i la manipulació, tot advertint que els expedients gràfics relligats (atles, anuaris, etc.) han de consultar-se a la biblioteca i que la cartoteca es responsabilitza només de documents en fulls solts 5 . Tots els mapes i plànols són registrats en l'Inventari de Cartografia. Cada document és descrit en una fitxa mestra, a la qual s'adjunten fitxes auxiliars amb la relació dels fulls de què es compon el document i amb la seva situació geogràfica. La classificació de les fitxes en l'Inventari es realitza pel tipus temàtic de document i atenent-ne l'escala. Anualment, el Departament de Geografia publica el Catàleg d'Informació Geogràfica, en el qual es classifiquen els mapes i els plànols per entrades toponímiques. Tant l'inventari com el catàleg poden consultar-se a la mateixa cartoteca o a la biblioteca ${ }^{6}$. En línies generals es pot considerar que era, i probablement encara és, una de les millors cartoteques del país.

\subsection{El laboratori de geografia física}

Pep Verd (1976-1977) va ser el primer professor de Geografia Física que va plantejar-se fer pràctiques de laboratori amb l'alumnat, però no hi havia instal-

5. Aquesta situació correspon al període que s'acaba amb el trasllat de la cartoteca a la Biblioteca d'Humanitats, ja que llavors els atles i els anuaris també estaven ubicats a la cartoteca.

6. Aquest paràgraf ha estat redactat per Pau Alegre, professor responsable de la cartoteca, i publicat a la Guia de l'estudiant durant diversos anys. 
lacions per realitzar-les a la Facultat. Seguint les passes de Pau Alegre, que havia aconseguit convertir l'aula 36 de l'espiga B9 parell en una cartoteca, també buscava reconvertir una aula en el laboratori de Geografia Física. Tanmateix, varen ser Manuel de Miró i Joan Sabí els que ho varen aconseguir el curs 19831984, amb una remodelació de l'espiga B9 parell, al final de la qual (antiga aula 47) s'hi van poder instal.lar diversos aparells, a més de les connexions d'aigua i de gas. L'objectiu principal en recerca era l'anàlisi de sòls, a més de les diverses pràctiques docents. Va continuar igual fins al primer trasllat del Departament a l'espiga B7 parell (primera planta totalment nova) el curs 2006-2007, i en el segon trasllat, un altre cop a l'espiga B9 parell, en una primera planta nova, el desembre del 2007, quan es va poder gaudir d'una ampliació substancial del laboratori i l'equipament.

\subsection{El Laboratori d'Informació Geogràfica i Teledetecció (LIGIT)}

L'any 1987 es va crear el Laboratori com a servei intern del Departament de Geografia. Va ser impulsat per Joan Nunes i ubicat temporalment a la cartoteca (a l'extrem de llevant de l'espiga B9 parell, planta baixa). Se centrava en l'ús dels sistemes d'informació geogràfica (SIG) per a la recerca aplicada. A l'entorn dels projectes DGICYT (1988-1991) i CICYT (1991-1994) sobre SIG en la gestió del territori a microescala i en àrees de muntanya ${ }^{8}$, però també en treballs sobre inventari i anàlisi d'usos del sòl en l'àmbit del Baix Llobregat (1986-1987) ${ }^{9}$, de Sant Adrià de Besòs $(1987)^{10}$, de la conurbació de Granollers $(1988-1989)^{11}$ i de l'Alta Garrotxa (1990-1991) ${ }^{12}$, varen ser una plataforma formativa en SIG i les seves aplicacions per a Joan Nunes, Xavier Pons, Enric Rodellas i David Comas, entre d'altres.

Uns quants anys més tard es trasllada a l'aula 36 de la mateixa espiga i quan se'n fa la remodelació, l'any 1995, a la facultat de les aules d'informàtica a l'espiga $\mathrm{B} 7$ parell, ocuparà la primera aula. Aquest nou espai coincideix amb l'aprovació a la Junta de Govern d'octubre de 1994 del LIGIT com a Servei Cientificotècnic de la UAB per a suport de la recerca. Finalment, el desembre de 2008 es trasllada a la localització definitiva, situada a l'extrem de llevant de l'espiga B9 parell planta baixa (curiosament, on va començar).

7. Web del Departament de Geografia de la UAB: <https://www.uab.cat/departament/geografia/>.

8. L'equip investigador estava format per Antoni F. Tulla (director TdD de Joan Nunes i Enric Rodellas), Joan Maria Roura (director TdD de Xavier Pons), Helena Estalella, Manuel de Miró, Pau Alegre, Gerda K. Priestley, David Guasch i Joan Nunes. Amb la col-laboració de Lluís Solé Sugrañes, de l'Institut Jaume Almera (CSIC).

9. Realitzat per Pau Alegre (dir.), J.A. Giménez, J. Nunes, L. Sancliment (Departament d'Informàtica) i F. Valen.

10. Elaborat per Pau Alegre amb la col-laboració de M. Tripiana

11. Realitzat per Joan Nunes (director), Àlex Coscuela, Núria Puigsureda, Montse Mercadé i Enric Rodellas.

12. Dirigit per Joan Nunes i Margarida Castañé, amb la col-laboració de Santi Martínez Illa i David Comas. 
La seva funció principal és el tractament informàtic de la informació geogràfica (tant cartogràfica com alfanumèrica) mitjançant la producció d'informació del territori organitzant-la en SIG (bases de dades que contemplen tant la informació temàtica com la definició geomètrica dels components), per tal de facilitar la consulta, la gestió i l'anàlisi territorial. Bàsicament realitza tres tipus d'activitats: suport a la recerca de docència (formació d'estudiants $\mathrm{i}$ professorat, postgrau i màster); transferència tecnològica i innovació (projectes de desenvolupament de tecnologies del SIG amb acords amb empreses i institucions externes), i difusió (formació específica i continuada de les TIG) ${ }^{13}$.

\section{La promoció de la recerca en geografia: Projecció cívica i cultural}

Quan es va concedir a Enric Lluch la distinció Jaume Vicens Vives, va explicar que «l'ensenyament universitari no pot deslligar-se de la recerca» i que "en els últims anys, la geografia a les nostres universitats ha experimentat un progrés enorme en les activitats de recerca fonamental i aplicada» (Lluch, 2000: 12). L'Enric va combinar la docència de la geografia amb la reflexió metodològica d'aquesta disciplina com una ciència social (Albet, 2007: 22-24), juntament amb una interpretació del món que va plasmar en diverses aportacions importants en l'àmbit de les enciclopèdies. Tanmateix, les seves contribucions a la recerca aplicada poden considerar-se les més innovadores de la geografia catalana durant les dècades de 1960 i 1970, quan hi dominava un enfocament més descriptiu. Un dels primers treballs empírics va ser la cerca de patrons dinàmics en l'estructura del transport públic a Catalunya (Lluch, Giral, Rexach, Riera i Torras, 1968). L'anàlisi metodològica i teòrica emprada es fonamentava en la nova geografia teoreticoquantitativa (Hagget, 1965) que s'estava desenvolupant a Anglaterra, on durant el curs 1957-1958 l'Enric va fer una estada d'un any a la Universitat de Liverpool, mantenint un lligam a través de les publicacions i les seves coneixences, $\mathrm{i}$ a uns altres països del nord (Hägerstrand, 1965) i del centre d'Europa (Christaller, 1933), que es projectaven a través de la geografia anglosaxona. L'any 1956 havia fet una estada al Trinity College (Dublín), amb una beca de l'Arts Council de la República d'Irlanda en haver completat els estudis d'Història i de Geografia a la Universitat de Barcelona (Nel.lo, 2013).

\subsection{La divisió territorial de Catalunya}

Durant la dècada de 1970 va iniciar-se, al Servei d'Estudis de Banca Catalana, la recerca per a una divisió territorial de Catalunya amb l'enfocament de Walter Christaller (1933), Brian J.L. Berry (1967) i Keith S.O. Beavon (1977), entre d'altres, de delimitar les àrees funcionals en el territori (Lluch, Riera, Giral i Soler, 1975). L'equip investigador (Grup d'Estudis Territorials) el formaven Enric Lluch, Joan Soler i Riber, Eugeni Giral i Pilar Riera, i una de les seves tasques principals va ser elaborar una enquesta preguntant on s'havia d'anar per

13. Extret de la sol-licitud per demanar ser un servei cientificotècnic. 
fer ús de determinats serveis o béns. L'enquesta es va passar a tots els municipis entre el meridià d'Osca ( $0^{\circ} 24^{\prime} 32^{\prime \prime}$ oest), el paral.lel de Castelló de la Plana (39 5 5' nord), la mar Mediterrània i la frontera amb Andorra, la Catalunya del Nord i Occitània.

L'any 1978, en el marc de la convocatòria de la Comissió d'Intercanvi Cultural entre Espanya i els Estats Units ${ }^{14}$, es va obtenir un projecte per a 3 anys i 5 milions de pessetes, dirigit per M. Dolors Garcia Ramon i Pilar Riera Figueras, amb la participació de 12 membres del Departament constituïts com a Institut Universitari d'Estudis Territorials (IUET) ${ }^{15}$. L'objectiu va ser completar l'estudi qualitatiu i quantitatiu d'una delimitació territorial funcional de Catalunya (Alegre et al., 1981), reforçant els coneixements teòrics i metodològics que van emprar-se en algunes de les tesis doctorals dels participants en aquesta recerca, com ara Helena Estalella (1982), Pilar Riera (1988) o Pau Alegre (1988). Es van consolidar els resultats de l'enquesta amb els fluxos dominants, en origen i destí, de les trucades telefoniques. Aquest enfocament positivista pretenia presentar resultats tècnicament consistents, ja que va haverhi un llarg període de congressos i debats sobre la millor organització territorial per a Catalunya.

Una altra part important de la recerca en aquest àmbit han estat les publicacions o la cura de reculls sistemàtics del que s'ha investigat o publicat en relació amb la divisió territorial de Catalunya. Les obres d'Enric Lluch i Oriol Nel.lo $(1983,1984,1985)$ com a recopiladors i comentaristes han esdevingut imprescindibles en aquesta tasca. També cal esmentar la participació activa del professorat de Geografia de la UAB en l'àmbit VIII d'Ordenació del Territori del Congrés de Cultura Catalana, que el 14 de novembre de 1976 va celebrar una sessió en el Seminari Diocesà de la Seu d'Urgell per tractar la temàtica de l'organització territorial de Catalunya (Riera, 1983).

\subsection{La geografia en el treball editorial}

Un dels mèrits principals d'Enric Lluch va ser apropar les principals novetats acadèmiques de França, els països anglosaxons i Itàlia als estudiosos de Catalunya, i d'Espanya, a través de les traduccions en les editorials catalanes. Des de la "Colección Ciencia Urbanística», de l'editorial Gustavo Gili, durant la dècada de 1970, primer, i molt especialment des de l'Editorial Oikos-Tau, de Vilassar de Mar, després, es varen anar publicant les obres innovadores d'urbanistes, geògrafs, demògrafs, sociòlegs i economistes, amb l'ajuda també del seu germà Ernest Lluch. El seu assessorament va arribar a unes altres editorials, com ara Vicens-Vives i Ariel, que varen recollir moltes de les seves propostes de traducció i publicació.

14. Conegut col-loquialment com el Tractat Hispano-Americà de les Bases Americanes.

15. M. Dolors Garcia Ramon, Pilar Riera, Enric Lluch, Eugeni Giral, Helena Estalella, Pau Alegre, Lluís Riudor, Carmen Gonzalo, Rosa Ascon, Maria Villanueva, Montserrat Terradas i Antoni F. Tulla. 
M. Dolors Garcia Ramon (2013: 203) i Abel Albet (2007: 22-24) van presentar la Geografía de la Sociedad Humana (Lluch, 1982-1984) com l'exemple més clar de la geografia entesa com a ciència social i com a saber interdisciplinari que sempre havia defensat Enric Lluch. «[...] La geografia és entesa com l'anàlisi, la interpretació i l'explicació de la dimensió econòmica, social, política cultural i històrica d'un territori» (Albet, 2007: 22). A la Geografía de la Sociedad Humana (Lluch, 1982-1984) s'hi desenvolupen les línies generals de la geografia que s'explicava a la UAB. Primer, dos volums on es presenten els coneixements i les interpretacions de la transformació "planetària» des de la perspectiva de les diverses ciències socials, donant-ne una visió global i transdisciplinària. Segon, sis volums «regionals» però amb una selecció més propera a l'organització territorial que no pas a la ubicació geogràfica en el globus terraqüi. Una part del professorat del Departament - Helena Estalella i Antoni F. Tulla (1981) — va participar en l'elaboració d'alguns capítols de l'obra, la qual encara cal tenir en compte per entendre els processos de transformació de l'espai, malgrat que hagi estat superada per la desaparició del sistema comunista en molts països i el domini del procés de globalització del capitalisme.

\subsection{Les relacions externes d'Enric Lluch i el Departament de Geografia de la UAB en l'àmbit de la geografia europea}

La creació d'una xarxa amb les universitats franceses va ser el fet més important dels primers anys. Al llarg de la dècada de 1970 va haver-hi una col.laboració entre els departaments de Geografia de Catalunya (UB i UAB) amb diverses universitats del sud de França (Tolosa de Llenguadoc, Montpeller, Ais de Provença, Bordeus i Pau), encara que bàsicament ho fou amb les dues primeres. Robert Ferras (1977), de la Universitat Paul-Valèry de Montpeller, va realitzar la thèse doctoral d'ètat sobre Barcelona, i juntament amb Roger Brunet varen fundar la Maison de la Géographie, especialitzada en geografia urbana i en cartografia. Bernard Kayser $(1972,1990)$, de la Universitat Tolosa II-Le Mirail, va treballar les petites ciutats franceses i més endavant la relació entre el camp i la ciutat. Va ser un dels primers geògrafs que va analitzar el periurbà i la revitalització dels àmbits agraris en el marc de les societats postindustrials. Claude i Georges Bertrand (2002) van ser, juntament amb Jean Tricart (Bret, Foucher, Giblin, Lacoste i Ghirardi, 1977), els que van plantejar la necessitat de realitzar una geografia física integral i el fet que la naturalesa és part del món social (Sabí, 1994). No oblidem que aquest és un principi bàsic de la nova geografia a la UAB. Una part del professorat del Departament va participar en reunions, conferències i estades en les universitats del Midi (Enric Lluch, M. Dolors Garcia Ramon, Helena Estalella, Jordi Borja, Antoni F. Tulla, Pau Alegre, Martí Boada, Joan Sabí, Joan Manuel Soriano, Gemma Cànoves, Asunción Blanco, Enric Mendizabal, Albert Pèlachs i Raquel Cunill, entre d'altres).

El primer marc de col-laboració amb Enric Lluch va ser el projecte Recherches régionales sur le Midi de la France et de la Catalogne (REMICA), finançat pel 
CNRS. Es va participar en estudis de geografia industrial (REMICA, 1974a) per poder fer un atles en la línia del realitzat per a la França de l'est, així com en la delimitació dels sistemes urbans, les petites i grans ciutats (REMICA, 1974b), que les dues universitats catalanes havien de fer per a Catalunya. El 27 de juny de 1977 es va organitzar a Tolosa la primera reunió d'un altre projecte del CNRS: GRECO 6: Processus d'urbanisation, i l'Enric Lluch va enviar-hi Helena Estalella, Jordi Borja i Antoni F. Tulla com a Grup Bellaterra d'Anàlisi Territorial de Barcelona II, ja que Barcelona I corresponia a Horacio Capel amb l'Equip Urbà. El responsable era Bernard Kayser, qui, juntament amb Geneviève Schektman-Labry (1982), va publicar alguns resultats d'aquesta recerca. L'any 1978 es va fer una altra reunió de treball a la Universitat de Tolosa II -Le Mirail, on Helena Estalella i Antoni F. Tulla varen acudir acompanyats per Pep Verd. Aquests contactes van facilitar la publicació en revistes franceses de la recerca en curs (Tulla, 1977). És important distingir, segons Enric Lluch, que la geografia es considerava una ciència «aplicable», políticament útil i socialment transformadora, i no pas merament una ciència «aplicada», cercant les innovacions conceptuals i metodològiques desenvolupades en uns altres països europeus (Albet, 2007: 27). La relació amb les noves orientacions de la geografia francesa ens ho va facilitar.

Un altre exemple interessant d'aquest període va ser la relació amb el Grup Dupont, de la Universitat Claude Bernard de Lió, i el Grup Chadule, de l'Institut de Geografia de la Universitat de Grenoble (Groupe Chadule, 1974). Tots dos varen crear una plataforma per introduir les tècniques i els mètodes quantitatius en geografia, cercant una aproximació autònoma de la geografia anglosaxona com altres autors de l'àmbit francòfon (Bailly i Polese, 1977; Beguin, 1979). M. Dolors Garcia Ramon, Lluís Riudor i Pau Alegre varen assistir a la reunió del Grup Dupont a Lió (1976), i a partir d'aquest contacte va afavorir-se la trobada que va tenir lloc l'any següent a la UAB. El Grup Dupont realitzava reunions de treball en diverses universitats franceses, però excepcionalment el 1977 va fer el Congrés Geo-Point en el nostre departament, amb la participació d'Enric Lluch, M. Dolors Garcia Ramon, Helena Estalella, Pau Alegre, Lluís Riudor i Antoni F. Tulla, entre d'altres.

Entre les relacions externes del Departament cal recordar la importància que varen tenir les estades que Anne Buttimer (1976) i David Harvey (1977) van fer al Departament de Geografia de la UAB, ja que va ser la primera vegada que visitaven una universitat de l'Estat espanyol i que molts dels contactes que varen establir va ser a través d'aquesta relació amb professorat del Departament, principalment amb M. Dolors Garcia Ramon.

\subsection{El desenvolupament de la recerca aplicada i la recerca bàsica al Departament de Geografia de la UAB}

Durant la dècada de 1980 s'inicia una intensiva col-laboració amb institucions públiques que donen lloc a un desenvolupament de la geografia aplicada al Departament. En el nou període democràtic en els ajuntaments i les ins- 
titucions estatals i autonòmiques hi ha la necessitat de promoure estudis de diagnosi i prognosi per a l'ordenació, la planificació i la gestió territorials. El Departament hi fa aportacions innovadores, com ara la col-laboració amb la Direcció General de Política Territorial (Generalitat de Catalunya) el curs 1980-1981 per fer el seguiment de la implantació del programa «Map analysis package» en el Sistema d'Informació Territorial de Catalunya (Alegre, 1983), en el marc de l'assignatura Anàlisi i Planificació del Territori del segon cicle de la llicenciatura de Geografia. Pau Alegre i Antoni F. Tulla (1986) van presentar algunes reflexions teòriques sobre aquest nou enfocament al món acadèmic de la geografia a l'Estat espanyol.

El curs 1981-1982 va ésser un període de col-laboració del Departament amb la Cambra Agrària de Girona. En especial es pretenia gestionar el cens agrari de $1982 \mathrm{amb}$ un enfocament diferent de com s'havia fet fins aleshores. Es realitzà una enquesta estadística a tots els municipis de la província de Girona per poder decidir quina estructura hauria de tenir el qüestionari del cens. Com a conseqüència es va obtenir l'estadística agrària de les comarques gironines (Estalella, Tulla i Terradas, 1983) ${ }^{16}$ emprant el SPSSx. L'any 1983 el Departament va implicar-se en la creació de l'Institut d'Estudis Metropolitans de Barcelona (IEMB), promogut per la Corporació Metropolitana de Barcelona, que estava presidida per Pasqual Maragall (alcalde de Barcelona) i per Antoni Serra Ramoneda (rector de la Universitat Autònoma de Barcelona). En aquest context, el curs 1983-1984, es varen encarregar l'estudi d'impacte del túnel de Vallvidrera i de l'autopista a Terrassa (Miró i Tulla, 1986) ${ }^{17}$ i, el 19841986, la vertebració del transport públic a l’Àrea Metropolitana de Barcelona (Lluch, Serra Ramoneda i Tulla, 1986) ${ }^{18}$, veritables escoles de formació en la geografia professional aplicada.

En un marc diferent va desenvolupar-se el programa «MAB-6 Urgellet Baridà» (1985-1989) amb un conveni entre l'Ajuntament de la Seu d'Urgell, la UAB, la UNESCO, ICONA i el Ministeri d'Obres Públiques i Transports (Ganyet i Tulla, 1993) ${ }^{19}$. És de destacar la participació de joves llicenciades i

16. Hi van participar com a coordinadors Helena Estalella, Antoni F. Tulla i Montserrat Terradas, professorat, amb la col-laboració de les llicenciades Anna Roca, Isabel Salamaña, Concepció Camps, Dolors Masó i Margarida Bech.

17. En aquest estudi hi varen participar els investigadors sèniors Manuel de Miró i Antoni F. Tulla (coord.), Àlex Vivar (arquitecte) i Josep Anguera (economista), amb els col-laboradors Purificació Alba, Isabel Clos i Joan Manuel Soriano (geògrafs) i Patricio Guzman (economista).

18. Codirigit per Antoni Serra Ramoneda, Enric Lluch i Antoni F. Tulla, hi varen participar els geògrafs i les geògrafes següents: Abel Albet, Àlex Tarroja, Carme Miralles, Marta Grabulosa, Neus Ríos, Oriol Nel.lo i Núria Valdovinos. Amb la col-laboració dels enginyers informàtics liderats per Tomàs Aluja.

19. Dirigit per Ramon Ganyet (enginyer) i Antoni F. Tulla (geògraf). Hi van participar a temps complet Xavier Campillo i Xavier Sanclimens (geògrafs), a més d'Albert Villarò (historiador). Els assessors en van ser Manuel de Miró i Helena Estalella, i els col-laboradors, Xavier Mateu, Joan Nunes i Santi Martínez Illa, a més d’altres professionals (enginyers i veterinaris). 
llicenciats en plans d'urbanisme municipals, com ara els de Granollers, Mataró i Rubí. En molts projectes hi van participar professorat i alumnat del Departament de Geografia i va ser el primer cop que es va poder intervenir en la diagnosi i en la prognosi de realitats complexes del territori.

En la recerca bàsica es varen obtenir els dos primers projectes del Programa Sectorial de Promoció General del Coneixement (DGICYT) en la convocatòria de 1987, que va ser la primera que va tenir més en compte les ciències socials i les humanitats. Tots dos corresponien a la consolidació de sis línies de recerca del Departament. El primer (PB87-0769)20, El papel de la mujer en la agricultura española: Un análisis desde la perspectiva del género, amb M. Dolors Garcia Ramon d'investigadora principal (IP), n'englobava tres: geografia rural, geografia des de la perspectiva de gènere i pensament geogràfic. $\mathrm{El}$ segon (PB87-0773) ${ }^{31}$, Experimentación y diseño de sistemas de información geográfica (SIG) adaptados a la gestión del territorio a micro y mesoescalas, amb Antoni F. Tulla d'investigador principal, tractava sobre l'anàlisi quantitativa i el SIG, la gestió dels espais naturals de muntanya i el planejament territorial. En la convocatòria següent (1990) es van continuar aquestes línies d'investigació i es van repetir els grups de recerca i els IP esmentats, amb Mujer y desarrollo rural en España. Alternativa a la actividad agraria: Un análisis desde la perspectiva de género (DGICYT PB90-0710) ${ }^{21}$ i Desarrollo de SIG para la gestión de áreas de montaña (CICYT INF91-0476) ${ }^{22}$. A partir d'aquest moment hi va haver un gran esclat de la recerca al Departament, però això ja correspon a un altre període.

\subsection{El Departament de Geografia i els instituts universitaris de recerca}

Finalment, cal esmentar la participació de professorat del Departament en la creació de dos centres de recerca que varen influir en la projecció social i en la producció científica de la geografia a la UAB. L'IEMB (Tulla, 1986) es va crear en forma de consorci arran d'un conveni signat el 18 d'octubre de 1984 entre la Corporació Metropolitana de Barcelona, la UAB i la Cambra Oficial de Comerç, Indústria i Navegació de Barcelona. Antoni F. Tulla, inicialment en la gestora i després com a director (1984-1987), i Oriol Nel.lo, com a director, (1988-1999) en varen ser els primers responsables. El Centre d'Estudis Demogràfics va ser creat el 1984 com a entitat pública gràcies a un acord entre la Generalitat de Catalunya i la UAB. En fou directora Anna Cabré (1984-2015) i amb aquesta mateixa línia va continuar la participació del professorat del Departament en diversos centres de recerca de creació posterior.

20. M. Dolors Garcia Ramon (IP), Gemma Cànoves, Josefina Cruz (USv), Isabel Salamaña, Montserrat Solsona, Antoni F. Tulla, Núria Valdovinos i Montserrat Vilariño (USC).

21. M. Dolors Garcia Ramon (IP) i el mateix equip, al qual es van incorporar Concepció Domingo (UV), Mireia Baylina i Lourdes Beneria (Universitat Cornell, EUA).

22. Vegeu els membres del projecte a la nota 17. 


\section{Reflexions finals}

Enric Lluch va plantejar la geografia com una ciència social que necessitava fer ús de coneixements bàsics d'economia, història i sociologia, però també de matèries instrumentals com ara matemàtiques, estadística, cartografia $o$ SIG, per poder fer front a una anàlisi global dels processos que tenen lloc al territori. Aquest fet posava en evidència la importància de la geografia com a disciplina transversal. A més, calia fer tot el treball, el docent $\mathrm{i}$ l'investigador, en equip — de vegades interdisciplinari- i mitjançant una discussió col-lectiva dels continguts i els enfocaments, tant de la recerca com de la docència.

Llavors, cal valorar la creació progressiva dels instruments científics (laboratoris, revista Documents d'Anàlisi Geogràfica, etc.) que no únicament van donar suport a la docència, sinó també als diversos projectes de recerca que varen enriquir els coneixements i les especialitats del Departament. De bon començament aquesta recerca $\mathrm{i}$ aquesta docència varen tenir una projecció social i cívica que enfortia la relació de la geografia amb la societat, cercant conèixer la realitat i buscant solucions als problemes que hi apareixien. El bagatge conceptual, així com moltes de les experiències tractades en la recerca, buscava els coneixements de la geografia en altres països innovadors. Aquesta relació internacional es va materialitzar amb estades del professorat del Departament en universitats d'Europa i d'Amèrica, organització de seminaris, recepció del professorat visitant i traducció d'un nombre significatiu de publicacions. Aquests nous coneixements varen posar-se en comú amb les experiències de nous enfocaments crítics a la història i unes altres disciplines afins, juntament amb les noves aportacions pedagògiques i els nous objectius en la recerca.

Dintre del Departament es van generar diversos grups de recerca, des de l'estudi i l'anàlisi de la divisió territorial de Catalunya fins als estudis de gènere, l'anàlisi de la població i les migracions o l'aplicació dels SIG a la gestió d'espais naturals protegits, fet que va culminar a la dècada de $1990 \mathrm{amb} 7$ SGR (grups de qualitat) de la Generalitat de Catalunya. La creació de noves universitats durant la dècada de 1990 va afavorir també que les característiques de la geografia a la UAB es reproduïssin a les altres institucions d'estudis superiors, com és el cas de la Universitat de Girona i, en menor dimensió, de la Universitat Pompeu Fabra.

El Departament, sorgit del grup cohesionat a l'entorn d'Enric Lluch, va consolidar-se institucionalment en aquest període inicial. No únicament pel reconeixement de la geografia a la UAB, sinó també a la resta del país i a l'estranger, a causa dels contactes internacionals i del procés gradual de desenvolupament de la recerca, en paral.lel i amb un diàleg dialèctic amb la docència. Aquesta cerca d'una investigació connectada amb la realitat, de forta base conceptual, també va implicar formar part del nucli promotor de centres de recerca com ara el IEMB o el CED, creats l'any 1984, entre d'altres. 


\section{Referències bibliogràfiques}

Albet, Abel (2007). Enric Lluch i Martín: L'obra escrita. Edició a cura d'Abel Albet i Mas. Barcelona: Societat Catalana de Geografia. IEC.

Alegre, Pau (1983). Una aplicació del Programa M.A.P. a Catalunya. Barcelona: Departament de Geografia. Universitat Autònoma de Barcelona / Direcció General de Política Territorial. Generalitat de Catalunya.

- (1988). Alternatives d'ordenació territorial: L'enfoc teòric. Bellaterra: Servei de Publicacions de la UAB. Tesi doctoral.

Alegre, Pau; Ascon, Rosa; Estalella, Helena; Garcia, Maria D.; Giralt, Emili; Gonzalo, M. a Carmen; Lluch, Enric; Riera, Pilar; Riudor, Lluís; Soler, Joan; Terrades, Montserrat i Tulla, Antoni F. (1981). "Àrees funcionals a la vegueria de Girona: Una primera aproximació». Revista del Col.legi Universitari de Girona, I, 251-287.

Alegre, Pau; Estalella, Helena; Riudor, Lluís i Tulla, Antoni F. (1983). «Geografía y renovación pedagògica: Enseñanza, demanda social y producción científica en geografía». Cuadernos de Pedagogía, 45, 4-7.

Alegre, Pau i Tulla, Antoni F. (1986). «Métodos de cuantificación aplicados a la planificación territorial». A: Métodos cuantitativos en geografia: Enseñanza, investigación y planeamiento. Madrid: Grupo de Métodos Cuantitativos, AGE, 240-268.

Bailly, Antoine i Polese, Mario (1977). «Processus urbans et modèles spatiaux: Écologie factorielle comparée Edmonton Québec». Le Géographe Canadien, XXI(1). <https://doi.org/10.1111/j.1541-0064.1977.tb00986.x>

Beavon, Keith S.O. (1977). Central Place Theory: A reinterpretation. Londres: Longman. Versió castellana: Geografía de las actividades terciarias: Una reinterpretación de la teoría de los lugares centrales. Vilassar de Mar: Oikos-Tau, 1981.

Beguin, Hubert (1979). Méthodes d'Analyse Géographique Quantitative. París: LITEC.

Benejam i Arguimbau, Pilar (2014). «Enric Lluch, el mestre». Documents d'Anàlisi Geogràfica, 60 (2), 219-233. <https://doi.org/10.5565/rev/dag.197>

BERrY, Brian J.L. (1967). Geography of retailing and market centers. Englewood Cliffs, N.J., USA: Prentice Hall. Versió castellana: Geografía de los centros de mercado y distribución al por menor. Barcelona: Vicens Vives, 1971.

Bertrand, Georges i Bertrand, Claude (2002). Une Géographie Traversière: L'environnement à Travers Territoires et Temporalités. París: Arguments.

Bret, Bernard; Foucher, Michel; Giblin, Béatrice; Lacoste, Yves i Ghirardi, Raymond (1977). Géographie Générale, physique et humaine. París: Fernand Nathan. Versió castellana: Geografía general, fisica y humana. Vilassar de Mar: Oikos-Tau, 1983.

Castells, Manuel (1972). La question urbaine. París: François Maspero. Versió castellana: La cuestión urbana. Madrid: Siglo XXI, 1974. Versió anglesa: The urban question: A Marxist approach. Londres: Edward Arnold, 1977.

Christaller, Walter (1933). Die zentralen Orte in Süddeutschland. Jena: G. Fischer. Versió anglesa: Central Places in Southern Germany. Englewood Cliffs, NJ: Prentice-Hall, 1966.

Estalella, Helena (1982). La propietat de la terra a les comarques gironines. Girona: Col.legi Universitari de Girona, 1984.

Estalella, Helena i Tulla, Antoni F. (1981). «Organización espacial del mundo rural». A: Geografía de la Sociedad Humana: Una perspectiva planetaria, vol. 2, cap. II. Barcelona: Planeta, 445-505. 
Estalella, Helena; Tulla, Antoni F. i Terradas, Montserrat (coords.) (1983). Estadistica agrària de les comarques gironines, 1981. Girona: Caixa Provincial de Girona.

Ferras, Robert (1977). Barcelone, croissance d'une métropole. París: Anthropos.

GAMBI, Lucio (1973). Una geografia per la storia. Torí: Einaudi.

Ganyet, Ramon i Tulla, Antoni F. (coords.) (1993). Mab-6 Alt Pirineu: Urgellet-Baridà. Madrid: Dirección General de Política Ambiental (MOPT).

Garcia Ramon, Maria Dolors (1989). «Género, espacio y entorno: ¿Hacia una renovación conceptual de la geografia? Una introducción». Documents d'Anàlisi Geogràfica, 14, 7-13.

- (2013). «Enric Lluch i Martín (1928-2012), In memoriam: Una mirada des del Departament de Geografia i Documents d'Anàlisi Geogràfica». Documents d'Anàlisi Geogràfica, 59 (2), 201-206. <https://doi.org/10.5565/rev/dag.98>

Groupe Chadule (1974). Initiation aux méthodes statistiques en géographie. París: Masson. Versió castellana: Iniciación a los métodos estadísticos en geografia. Barcelona: Ariel, 1980.

Hadjimichalis, Costis (2017). «Encounters with Ray Hudson: A very personal note». European Urban and Regional Studies, 24 (2), 126-128. <https://doi.org/10.1177/0969776416689219>

Hägerstrand, Thorsten (1965). «A Monte Carlo approach to diffusion». Archives Européennes de Sociologie, 6, 43-47. <https://doi.org/10.1017/S0003975600001132>

Haggett, Peter (1965). Locational Analysis in Human Geography. Londres: Edward Arnold. Versió castellana: Análisis locacional en la geografia humana. Barcelona: Gustavo Gili, 1975.

Harvey, David (1973). Spatial Justice and the City. Londres: Edward Arnold. Versió castellana: Urbanismo y desigualdad social. Madrid: Siglo XXI, 1977.

Kayser, Bernard (1972). «Les petites villes françaises». Revue de géographie alpine, 60 (2), 269-284. <https://doi.org/10.3406/rga.1972.1266>

- (1990). La renaissance rurale: Sociologie des campagnes du monde occidentale. París: Armand Colin.

Kayser, Bernard i Schektman-Labry, Geneviève (1982). "Le troisième couronne périurbaine: Une tentative d'identification». Revue Géographique des Pyrénées et du sud-ouest, 53 (1), 27-34. <https://doi.org/10.3406/rgpso.1982.3673>

LluCH, Enric (2000). "L'ensenyament universitari no pot deslligar-se de la recerca». L'Autònoma: Publicació de la Universitat Autònoma de Barcelona, 141, 12.

Lluch, Enric (dir.) (1982-1984). Geografia de la Sociedad Humana. 8 vol. Barcelona: Planeta.

Lluch, Enric; Giral, Eugeni; Rexach, Maria Rosa; Riera, Pilar i Torras, Jaume (1968). «Evolució de les àrees de trànsit dels autobusos de línia a Catalunya, 19341964». Banca Catalana: Publicación de Información Económica, 8, 16-28.

Lluch Martín, Enric; Riera Figueras, Pilar; Giral Quintana, Eugeni i Soler Riber, Joan (1975). «Estructura Funcional del Territorio: Un anàlisis empírico». A: Economía Regional en España: 1a Reunión General de Servicios de Estudios Econòmicos, I, 328-337. Madrid: Editorial Moneda y Crédito. 
LluCh, Enric i Nel-Lo, Oriol (a cura de) (1983). La gènesi de la divisió territorial de Catalunya: Edició de documents de l'arxiu de la Ponència (1931-1936). Barcelona: Diputació de Barcelona.

- (1984). El debat de la divisió territorial de Catalunya (1939-1983): Edició d'estudi, propostes $i$ documents. Barcelona: Diputació de Barcelona.

- (1985). «Codicil sobre el debat de la Divisió Territorial de Catalunya (19841985)». Arrel, 11, 25-35.

Lluch, Enric; Serra Ramoneda, Antoni i Tulla, Antoni F. (coords.) (1986). El transport públic en la futura vertebració del territori metropolità de Barcelona. 3 vol. Barcelona: Institut d'Estudis Metropolitans de Barcelona i Ferrocarril Metropolità de Barcelona.

Miró, Manuel de i Tulla, Antoni F. (1986). "L’impacte del Túnel i Autovia de Vallvidrera al territori: Un exemple de geografia aplicada». Documents d'Anàlisi Geogràfica, 8-9, 39-70.

Nel-LO, Oriol (2013). Quatre lliçons d'Enric Lluch. Barcelona: Institut d'Estudis Catalans (4 de juny de 2013).

Okyay, Tarik; Yazar, V. i Altaban, Ö. (1975). «Housing and environmental standards as a product of the free market mechanism. An exemple: Ankara». M.E.T.U. Journal of the Faculty of Architecture, 1 (2), 271-294.

REMICA (1974a). "Les grands établissements industrials dans le Midi de la France et de la Catalogne». Serie Remica, 5. Tolosa.

- (1974b). «Sistemas espaciales y estructuras regionales». Revista de Geografía, VIII, 1-2, 5-17.

Rhind, David W. (1991). "Geographical Information Systems: Principles and Applications». A: Maguire, D.J.; Goodchild, M.F. i Rhind, D.W. The Geoinformation Group (the Big GIS Book). Harlow: Longman / Nova York: John Wiley \& Sons Inc.

Rhind, David W. i Hudson, Ray (1980). Land Use. Londres: Methuen.

Riera Figueras, Pilar (1983). La nova divisió territorial de Catalunya. Bellaterra: Departament de Geografia. Universitat Autònoma de Barcelona.

- (1988). Les àrees funcionals de Catalunya. Bellaterra: Servei de Publicacions de la UAB. Tesi doctoral.

Riquer, Borja de i Molinero, Carme (dirs.) (2018). L'audàcia del coneixement: 50 anys $U A B$. Bellaterra: Servei de Publicacions de la Universitat Autònoma de Barcelona.

SABí, Joan (1994). «La géographie et l'environnement: La géographie physique en question. Journée de bilan et de prospective». Documents d'Anàlisi Geogràfica, 25, 193-201.

Tulla, Antoni F. (1977). «Les deux Cerdagnes: Exemple de transformations économiques asymétriques de part et d'autre de la frontière des Pyrenées». Revue Géographique des Pirénées et du Sud-Ouest, 48 (4), 404-424. <https://doi.org/10.3406/rgpso.1977.3524>

- (1986). "L'Institut d'Estudis Metropolitans de Barcelona». Documents d'Anàlisi Geogràfica, 8-9, 3-16. 
